\title{
Catalytic Activity of an Iron-Based Water Oxidation Catalyst: Substrate Effects of Graphitic Electrodes
}

\author{
Konstantin G. Kottrup, ${ }^{\dagger}$ Silvia D’Agostini, ${ }^{\dagger}$ Phebe H. van Langevelde, ${ }^{\dagger}$ Maxime A. Siegler, \\ and Dennis G. H. Hetterscheid*, ${ }^{*}$ \\ ${ }^{\dagger}$ Leiden Institute of Chemistry, Leiden University, P.O. Box 9502, 2300 RA Leiden, The Netherlands \\ ${ }^{\ddagger}$ Department of Chemistry, Johns Hopkins University, 3400 North Charles Street, Baltimore, Maryland 21218, United States
}

\section{Supporting Information}

ABSTRACT: The synthesis, characterization, and electrochemical studies of the dinuclear complex $[(\mathrm{MeOH}) \mathrm{Fe}(\mathrm{Hbbpya})-\mu$-O$(\mathrm{Hbbpya}) \mathrm{Fe}(\mathrm{MeOH})](\mathrm{OTf})_{4}$ (1) (with Hbbpya $=N, N$-bis $\left(2,2^{\prime}\right.$ bipyrid-6-yl)amine) are described. With the help of online electrochemical mass spectrometry, the complex is demonstrated to be active as a water oxidation catalyst. Comparing the results obtained for different electrode materials shows a clear substrate influence of the electrode, as the complex shows a significantly
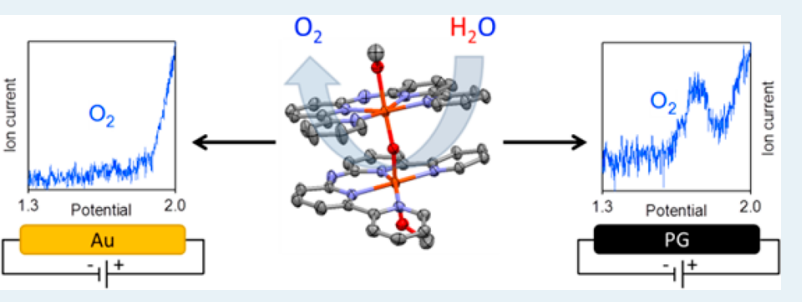
lower catalytic overpotential on graphitic working electrodes in comparison to other electrode materials. Cyclic voltammetry experiments provide evidence that the structure of complex 1 undergoes reversible changes under high-potential conditions, regenerating the original structure of complex 1 upon returning to lower potentials. Results from electrochemical quartz crystal microbalance experiments rule out that catalysis proceeds via deposition of catalytically active material on the electrode surface.

KEYWORDS: water oxidation, iron, homogeneous catalysis, electrode effects, electrochemistry

\section{INTRODUCTION}

With economic growth and the expansion of modern societies, the global demand for energy increases steadily every year. ${ }^{1}$ Currently, this demand is still largely met by the unsustainable consumption of fossil fuels. As the reserves of fossil fuels decrease and the effect of $\mathrm{CO}_{2}$ emissions on the climate becomes more and more apparent, the development of new technologies for a sustainable energy infrastructure based on the conversion of solar energy to a chemical fuel has become of critical importance in the 21st century. Among those new technologies, realizing the economically viable splitting of water into its elements has emerged as a key target. ${ }^{2}$ One of the biggest challenges in realizing such a process is finding sufficiently efficient and robust catalysts for the water oxidation reaction that are based on readily available materials.

Despite considerable advancements in the field of homogeneous water oxidation catalysis over the past decade, the best catalysts that have been developed so far still rely on scarce and expensive materials such as ruthenium and iridium. ${ }^{3-12}$ In order for solar fuels to become a competitive alternative to fossil fuels on a global scale, water oxidation catalysts based on abundant and affordable first-row transition metals are needed. Among those metals, iron is one of the prime candidates for the development of new catalysts due to its high abundance on earth, its rich redox chemistry, and its prominent role in oxygen binding and oxygen transfer in many metalloproteins and active sites of enzymes found in nature. ${ }^{13}$ In recent years, more and more examples of molecular iron based water oxidation catalysts have been published in the literature. ${ }^{14-28}$ However, most examples of iron-based catalysts reported so far are still outperformed by catalysts based on ruthenium and iridium in terms of turnover numbers, ${ }^{19-28}$ turnover frequencies, ${ }^{19-28}$ overpotentials, $^{18-21}$ and Faradaic efficiencies. ${ }^{19,20}$ While ruthenium- and iridium-based systems have been reported to yield TONs in excess of $100000^{29}$ and TOFs on the order of $10000 \mathrm{~s}^{-1}, 30$ systems based on first-row transition metals such as iron, cobalt, and manganese generally exhibit low doubledigit turnover numbers and turnover frequencies on the order of $1 \mathrm{~s}^{-1}$ or lower. 9 While for ruthenium-based systems overpotentials below $200 \mathrm{mV}^{31}$ have been reported, overpotentials for water oxidation of first-row transition-metal systems-if reported-generally exceed $500 \mathrm{mV} .{ }^{18-21,32}$ One notable exception is the pentanuclear iron-based water oxidation catalyst that was recently reported by Masaoka et al. Although the catalyst does not work in aqueous solution, a respectable turnover frequency of $1900 \mathrm{~s}^{-1}$ was found in acetonitrile/water mixtures. ${ }^{17}$

The majority of the iron complexes that have been reported so far have been studied using sacrificial oxidants such as cerium(IV) ammonium nitrate (CAN) and periodate. In recent years, however, more and more evidence has emerged, demonstrating that these oxidants are often directly involved in the reaction mechanism aside from being simply innocent outer-sphere one-electron acceptors. ${ }^{33-39}$ Previously, we

Received: September 26, 2017

Revised: December 15, 2017

Published: December 21, 2017 
investigated iron-based complexes bearing macrocyclic tetraazatype ligands for their potential as electrocatalysts for the water oxidation reaction. ${ }^{18}$ Using electrochemistry in general and online electrochemical mass spectrometry (OLEMS) in particular, we were able to demonstrate the importance of different structural motifs for the electronics of the complex and its activity in catalyzing the water oxidation reaction.

A very important aspect in homogeneous electrocatalysis which has so far received only little attention is the influence of the electrode surface on the reaction mechanisms involving homogeneous electrocatalysts. If the electron transfer between the catalyst and the electrode proceeds exclusively via an outersphere mechanism, one would expect only a small influence of the electrode material. However, in the case of an inner-sphere mechanism involving adsorption of the catalyst on the electrode surface, a much larger influence of the electrode material is to be expected. ${ }^{40}$ Despite the potentially very important role of the electrode material in electrochemical water oxidation catalysis, only a few examples of research on this subject can be found in the literature. ${ }^{41,42}$

In this report we introduce the dinuclear oxo-bridged iron complex $[(\mathrm{MeOH}) \mathrm{Fe}(\mathrm{Hbbpya})-\mu$-O-(Hbbpya) $\mathrm{Fe}(\mathrm{MeOH})]$ $(\mathrm{OTf})_{4}\left(1 ;\right.$ Hbbpya $=N, N$-bis $\left(2,2^{\prime}\right.$-bipyrid-6-yl $)$ amine $)$. The complex is active as an electrocatalyst for water oxidation, which is in line with previous reports that have found dinuclear oxygen-bridged iron complexes to be active water oxidation catalysts. ${ }^{14-16,23,24}$ However, in the case of complex $\mathbf{1}$ we show that the water oxidation activity is strongly dependent on the nature of the electrode material, resulting in a significantly lower overpotential on graphitic working electrodes in comparison to other electrode materials.

\section{RESULTS AND DISCUSSION}

Synthesis and Characterization. Complex 1 was synthesized by combining methanolic solutions of iron(II) triflate and Hbbpya under argon (Scheme 1). After the mixture

Scheme 1. Synthesis of Complex 1
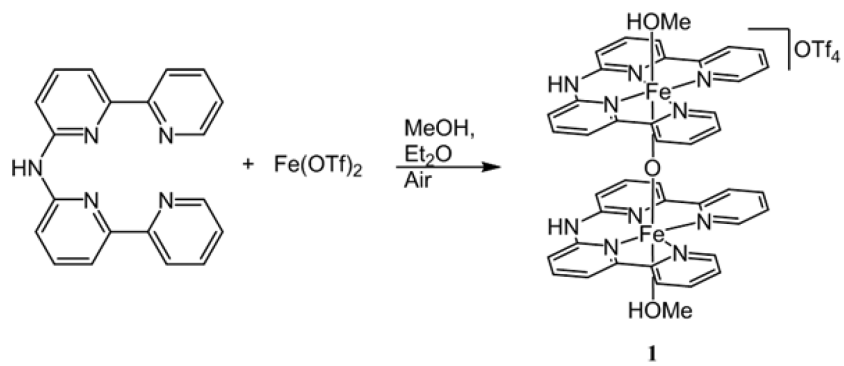

was stirred overnight and the solvent was subsequently evaporated, a crude red-brownish solid was obtained. To isolate complex 1, the crude product was recrystallized in air by vapor diffusion of $\mathrm{Et}_{2} \mathrm{O}$ into a concentrated methanolic solution of the crude product, resulting in dark brown crystals of complex 1 . The crystalline material was characterized by singlecrystal X-ray crystallography, mass spectrometry, and elemental analysis. An X-ray structure determination unequivocally reveals the dimeric nature of complex $\mathbf{1}$ (Figure 1). All relevant bond angles and distances of the crystal structure of $\mathbf{1}$ are summarized in Table S2 in the Supporting Information.

The complex consists of two iron sites bridged by an oxo ligand. Each iron site bears an Hbbpya ligand and an axial methanol ligand following a distorted-octahedral geometry

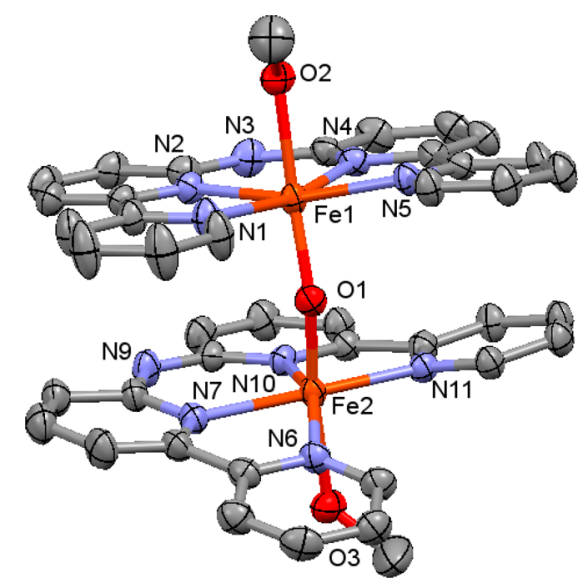

Figure 1. Displacement ellipsoid plot (50\% probability level) of complex 1 at $110(2) \mathrm{K}$. All hydrogen atoms and the four triflate counterions have been omitted for clarity.

together with the bridging oxo ligand. The measured bond angles and bond distances are very similar for both iron sites. All eight $\mathrm{Fe}-\mathrm{N}$ bond distances fall into a narrow range of 2.11-2.14 $\AA$. Both $\mathrm{N}-\mathrm{Fe}-\mathrm{N}$ bond angles of the six-membered chelate rings of 87.0 and $87.1^{\circ}$, respectively, are close to the ideal $90^{\circ}$ of a square-planar structure. The $\mathrm{N}-\mathrm{Fe}-\mathrm{N}$ angles of the five-membered chelate rings are more acute at $78.2-78.7^{\circ}$, while the open $\mathrm{N}-\mathrm{Fe}-\mathrm{N}$ bond angles are much wider at 114.2 and $114.6^{\circ}$. Both internal $\mathrm{Fe}-\mathrm{O}$ bond distances between the iron centers and the bridging oxo ligand of $1.78 \AA$ are shorter than the external $\mathrm{Fe}-\mathrm{O}$ bonds distances to the methanol ligands of $2.15 \AA$. These values are in good agreement with values previously reported by Thummel et al. for the iron complexes $\left[\left(\mathrm{H}_{2} \mathrm{O}\right) \mathrm{Fe}(\mathrm{ppq})-\mu-\mathrm{O}-(\mathrm{ppq}) \mathrm{FeCl}\right] \mathrm{Cl}_{3} \quad(2 ; \mathrm{ppq}=2$ (pyrid-2'-yl)-8-(1", 10" -phenanthrolin-2" -yl)quinoline) and $\left[\mathrm{Fe}(\mathrm{dpa}) \mathrm{Cl}_{2}\right] \mathrm{Cl}$ (3; dpa $=N, N$-bis $(1,10$-phenanthrolin-2-yl)$\mathrm{N}$-isopentylamine) and the values previously reported by Marchetti et al. for the iron complex $\left[\left(\mathrm{H}_{2} \mathrm{O}\right) \mathrm{Fe}(\mathrm{L})-\mu\right.$-O(L) $\left.\mathrm{Fe}\left(\mathrm{H}_{2} \mathrm{O}\right)\right]\left(\mathrm{ClO}_{4}\right)_{4} \quad\left(4 ; \mathrm{L}=2,2^{\prime}: 6^{\prime} 2^{\prime \prime}: 6^{\prime \prime}, 2^{\prime \prime \prime}\right.$-quaterpyridine). ${ }^{15,43}$

While the $\mathrm{Fe}-\mathrm{O}-\mathrm{Fe}$ bond angles in the structures of complexes 2 and 4 were measured at 171.3 and $180^{\circ}$, respectively, the $\mathrm{Fe}-\mathrm{O}-\mathrm{Fe}$ bond angle of $155.78(18)^{\circ}$ that was measured for complex 1 deviates notably from the expected $180^{\circ}$. The atoms of the two Hbbpya ligands are also not aligned directly on top of each other in the crystal structure. Instead, each atom of one Hbbpya ligand is offset with respect to its counterpart in the other Hbbpya ligand by a rotation around the $\mathrm{Fe}-\mathrm{Fe}$ axis of about $44^{\circ}$ (Figure $\mathrm{S} 1$ in the Supporting Information). Furthermore, the two Hbbpya ligands differ in their conformation. While one Hbbpya ligand is fairly planar with an internal torsion angle of only $3.0^{\circ}$ (Figure S2 in the Supporting Information), one of the two bipyridine moieties of the other Hbbpya ligand is twisted out of plane, resulting in a considerably greater internal torsion angle of $16.4^{\circ}$ (Figure S2). As a result, the distances between the two Hbbpya ligands vary from a relatively narrow range of $3.37-3.55 \AA$ for the two bipyridine moieties in face parallel alignment to a much wider spread of 3.52-4.40 $\AA$ for the other two bipyridine moieties (Figure S3 in the Supporting Information). These features suggest that the distortions in the structure are compensated for by favorable $\pi-\pi$ interactions between the aromatic systems of the two Hbbpya ligands. The observed distances of 3.37-3.55 

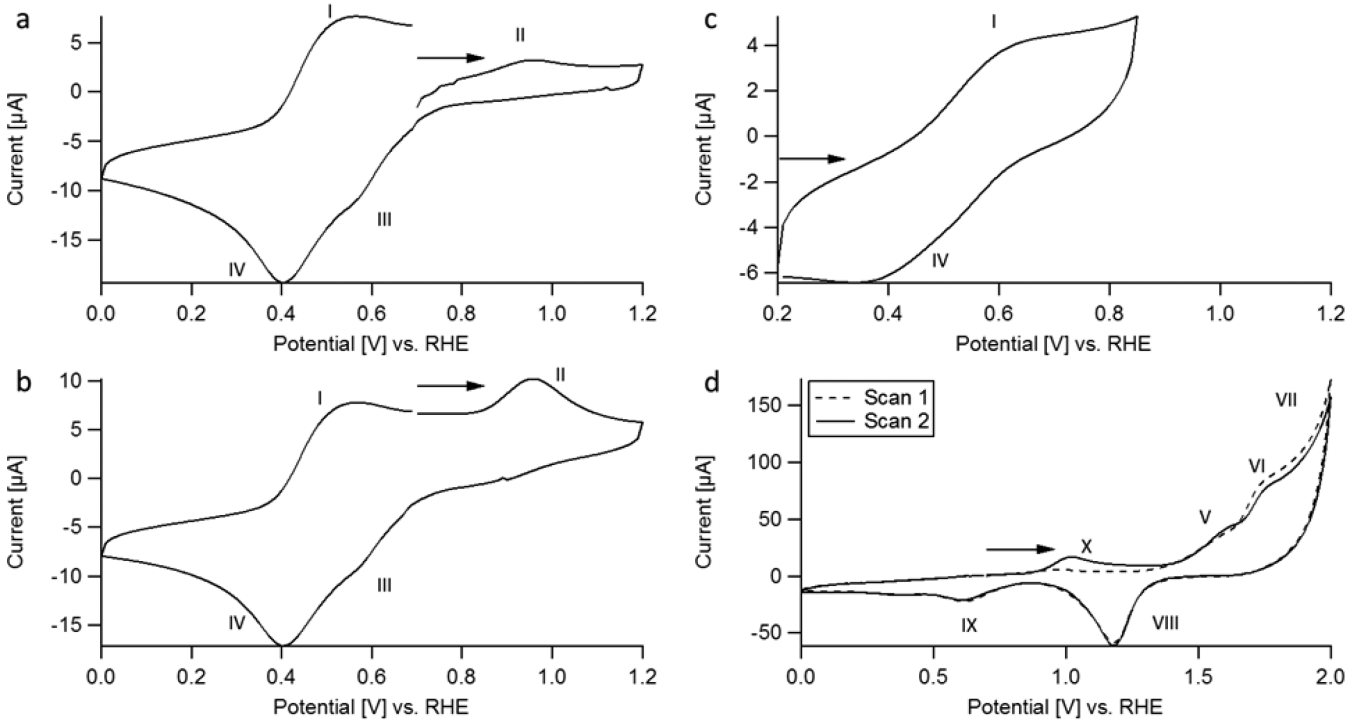

Figure 2. Results of CV experiments of $0.5 \mathrm{mM}$ complex 1 in a $0.1 \mathrm{M} \mathrm{Na}_{2} \mathrm{SO}_{4}$ solution using a gold working electrode at a scan rate of $100 \mathrm{mV} / \mathrm{s}$. Arrows indicate the direction of each cycle. (a) First scan between 0.0 and $1.2 \mathrm{~V}$ vs RHE, starting at $0.7 \mathrm{~V}$ vs RHE. (b) Second scan between 0.0 and $1.2 \mathrm{~V}$ vs RHE, starting at $0.7 \mathrm{~V}$ vs RHE. (c) Second scan between 0.2 and $0.8 \mathrm{~V}$ vs RHE, starting at $0.2 \mathrm{~V}$ vs RHE. (d) First and second scans between 0.0 and $2.0 \mathrm{~V}$ vs RHE, starting at $0.7 \mathrm{~V}$ vs RHE.

$\AA$ fall well within the range commonly found for such interactions. $^{44}$

Next to the structural data for the crystalline material, mass spectrometry data confirm that the complex exists exclusively as a dimeric species in aqueous solution (Figure S4 in the Supporting Information). UV-vis measurements of the aqueous solution show no change in the absorption spectrum for at least $10 \mathrm{~h}$, confirming that the dimeric species is stable over time (Figure S5 in the Supporting Information).

Electrochemical Experiments. Although complex 1 dissolves in water, it hardly dissolves in solutions containing perchlorate anions. As a consequence, sodium sulfate was chosen as the most appropriate electrolyte, even though the sulfate ion has been shown to inhibit water oxidation activity slightly in comparison to perchlorate in some cases. ${ }^{10}$ In $0.1 \mathrm{M}$ $\mathrm{Na}_{2} \mathrm{SO}_{4}$ complex 1 does dissolve up to concentrations of 0.5 $\mathrm{mM}$.

Electrochemistry on Gold. Using a gold working electrode, the redox behavior of complex $\mathbf{1}$ was investigated by performing cyclic voltammetry $(\mathrm{CV})$ experiments across different scan ranges. Figure $2 \mathrm{a}, \mathrm{b}$ shows the respective first and second scans of a CV experiment between 0.0 and $1.2 \mathrm{~V}$ vs a reversible hydrogen electrode (RHE), with each scan started at $0.7 \mathrm{~V}$ vs RHE. In the second scan (Figure $2 \mathrm{~b}$ ), four distinct redox events can be observed, indicated as I-IV in the figure. I and IV are tentatively assigned to the $\left[\mathrm{Fe}^{\mathrm{II}} \mathrm{Fe}^{\mathrm{II}}\right] /\left[\mathrm{Fe}^{\mathrm{II}} \mathrm{Fe}^{\mathrm{III}}\right]$ transition and $\mathrm{II}$ and $\mathrm{III}$ to the $\left[\mathrm{Fe}^{\mathrm{II}} \mathrm{Fe}^{\mathrm{III}}\right] /\left[\mathrm{Fe}^{\mathrm{III}} \mathrm{Fe}^{\mathrm{III}}\right]$ transition. This assignment is supported by the fact that the oxidation event II at $0.9 \mathrm{~V}$ is largely absent in the first forward scan (Figure 2a) as long as a starting potential above both reduction events III and IV is chosen. Since the complex is introduced in the $\left[\mathrm{Fe}^{\mathrm{III}} \mathrm{Fe}^{\mathrm{III}}\right]$ state and the selected resting potential of $0.7 \mathrm{~V}$ lies above both reduction events, hardly any $\left[\mathrm{Fe}^{\mathrm{II}} \mathrm{Fe}^{\mathrm{III}}\right]$ is present to be oxidized in the first scan. Further evidence for this assignment is obtained when the starting potential is set to 0.2 $\mathrm{V}$ and the scan range is selected to stay below the onset of second oxidation event between 0.8 and $1.0 \mathrm{~V}$. The corresponding voltammogram between 0.2 and $0.8 \mathrm{~V}$ (Figure 2c) only shows transitions I and IV, showing that reduction wave IV is connected to oxidation wave I and that reduction wave III is connected to oxidation wave II.

When the scan range is set to $0.0-2.0 \mathrm{~V}$, a shift in the redox behavior is observed. Starting again at $0.7 \mathrm{~V}$, the first forward scan does not show any new oxidation events below $1.5 \mathrm{~V}$ (Figure $2 \mathrm{~d}$ ). Above $1.5 \mathrm{~V}$ three oxidation events are observed, labeled V-VII, which can be attributed to gold oxide formation (V and VI) and water oxidation (VII), respectively (vide infra).

In the backward scan, two reduction events can be seen, one at $1.2 \mathrm{~V}$ (VIII; gold oxide reduction) and one at $0.6 \mathrm{~V}$ (IX). In the second forward scan, one additional oxidation event $(\mathrm{X})$ appears at $1.0 \mathrm{~V}$. Instead of the four transitions I-IV that were initially observed for the $\mathrm{Fe}^{\mathrm{II}} / \mathrm{Fe}^{\mathrm{III}}$ transitions on scanning between 0.0 and $1.2 \mathrm{~V}$, only the two new and broad redox events IX and $\mathrm{X}$ can be observed below $1.2 \mathrm{~V}$ in subsequent cycles after reaching $2.0 \mathrm{~V}$. This difference indicates that complex 1 undergoes structural changes at high potentials. Scanning from 0.0 to $2.0 \mathrm{~V}$ and recording 50 scans between 0.0 and $1.2 \mathrm{~V}$ at $100 \mathrm{mV} / \mathrm{s}$ immediately afterward show that this change in redox behavior reverts over time; waves IX and X disappear while waves I-IV reappear during prolonged scanning, showing that the change to the structure of complex 1 is reversible (Figure 3).

Evidence that the irreversible oxidation wave VII belongs to the oxygen evolution reaction was obtained via OLEMS experiments. In OLEMS experiments the $m / z$ traces of selected gaseous species sampled in solution in close proximity to the surface of the working electrode are recorded during electrochemical experiments. ${ }^{45}$ Figure 4 shows the second forward scan of an OLEMS experiment, recorded while the potential was cycled between 1.3 and $2.0 \mathrm{~V}$ at $1 \mathrm{mV} / \mathrm{s}$, with a starting potential of $1.3 \mathrm{~V}$. The bottom panel of Figure 4 shows the corresponding current trace. Since the gold electrode was already oxidized during the first scan of the OLEMS experiment, the gold oxidation waves V and VI are absent in the second scan, leaving only the oxidation wave VII. The top panel of Figure 4 shows the mass trace for $\mathrm{O}_{2}$ recorded during 

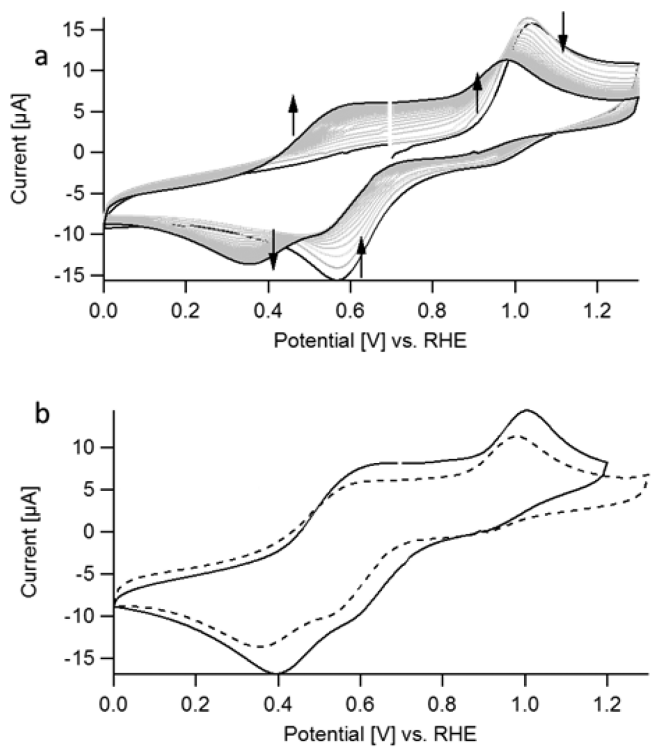

Figure 3. Demonstration of the evolution over time of the redox events observed after initially scanning to $2.0 \mathrm{~V}$ vs RHE with a gold working electrode in the presence of $0.5 \mathrm{mM}$ complex 1 . The change in time is visualized with $\mathrm{CV}$ experiments between 0.0 and $1.3 \mathrm{~V}$ vs RHE at a scan rate of $100 \mathrm{mV} / \mathrm{s}$. All experiments were performed in a $0.1 \mathrm{M} \mathrm{Na}_{2} \mathrm{SO}_{4}$ solution. (a) 50 cycles between 0.0 and $1.3 \mathrm{~V}$ vs RHE, starting at $0.7 \mathrm{~V}$ vs RHE, recorded immediately after scanning to $2.0 \mathrm{~V}$ vs RHE. The first and last scans are displayed in black, while the intermediate scans are displayed in gray. Arrows indicate the change in the current profile over time. (b) Comparison between the redox events before scanning to $2.0 \mathrm{~V}$ vs RHE (solid line) and scan number 50 after scanning to $2.0 \mathrm{~V}$ vs RHE (dashed line).

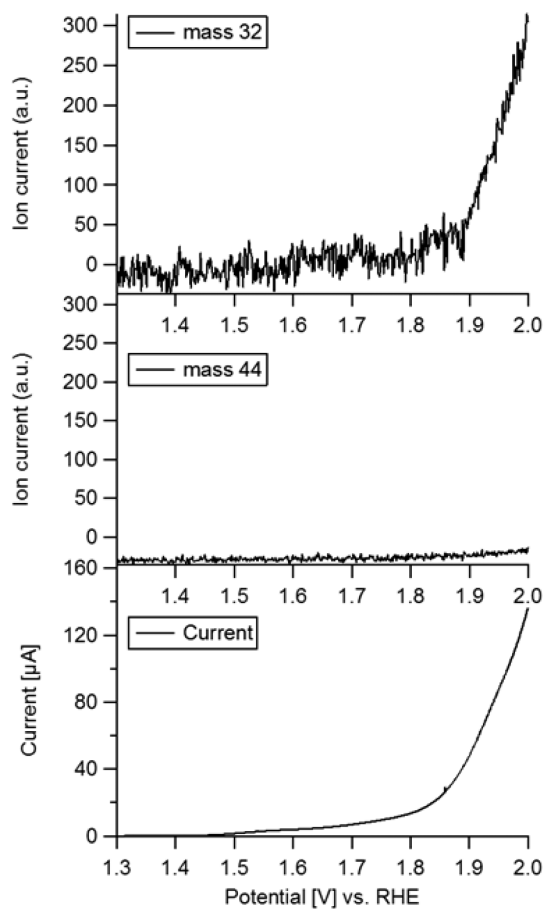

Figure 4. Results of an OLEMS measurement of $0.5 \mathrm{mM}$ complex 1 with a gold working electrode in a $0.1 \mathrm{M} \mathrm{Na}_{2} \mathrm{SO}_{4}$ solution (scan range $1.3-2.0 \mathrm{~V}$ vs RHE, scan rate $1 \mathrm{mV} / \mathrm{s}$, starting at $1.3 \mathrm{~V}$ vs RHE). Shown is the forward scan of a CV experiment with the $m / z$ trace for $\mathrm{O}_{2}$ (top), the $m / z$ trace for $\mathrm{CO}_{2}$ (middle), and the corresponding current (bottom). the experiment, which shows a clear onset of oxygen evolution at about $1.9 \mathrm{~V}$ that correlates well with the oxidative current shown in the bottom panel of Figure 4. Since previous reports ${ }^{46-49}$ have shown that electrocatalytic water oxidation by metal complexes is often preceded or accompanied by oxidative degradation of ligands, which can result in the formation of $\mathrm{CO}_{2}$, we also recorded the mass trace of $\mathrm{CO}_{2}$ via OLEMS (Figure 4, middle). The result shows that, in comparison to oxygen, no significant amounts of $\mathrm{CO}_{2}$ are being formed during the experiment.

The gold electrode in itself is in principle capable of oxidizing water at high potentials; however, in previous work no detectable amounts of oxygen were found below $2.0 \mathrm{~V}$ for a gold working electrode in the absence of any additional catalyst. ${ }^{50}$ While there is still some oxidative current beyond gold oxidation that is visible in blank measurements, OLEMS measurements with a gold working electrode in a $0.1 \mathrm{M}$ $\mathrm{Na}_{2} \mathrm{SO}_{4}$ electrolyte solution in the absence of complex 1 confirm that there is no detectable amount of oxygen being formed below $2.0 \mathrm{~V}$ under those conditions (Figure S6 in the Supporting Information).

Electrochemistry on Carbon. The electrochemistry that is observed for complex $\mathbf{1}$ on a pyrolytic graphite (PG) electrode shows a significant difference from the results obtained for a gold working electrode. For both electrodes, complex 1 initially shows redox waves I-IV (Figure 5a), which disappear when the potential is increased to $2.0 \mathrm{~V}$, resulting in the formation of a new species, giving rise to redox waves IX and X (Figure 5b). Likewise, for both electrode materials the disappearance of waves IX and $\mathrm{X}$ accompanied by the reappearance of waves IIV can be seen over time when the potential is kept below $1.2 \mathrm{~V}$ after initially scanning to $2.0 \mathrm{~V}$ (Figure $5 c$,d). However, in contrast to the electrochemistry on gold, an additional and persistent irreversible oxidation wave can be observed on PG with an onset potential of about $1.6 \mathrm{~V}$ (Figure 6, bottom). While the separation between the two waves above $1.6 \mathrm{~V}$ is not very well resolved at higher scan rates $(100 \mathrm{mV} / \mathrm{s}$, Figure $5 \mathrm{~b})$, it becomes much more pronounced at lower scan rates $(10 \mathrm{mV} / \mathrm{s}$ and slower, Figure 6, bottom, and Figure 7b).

OLEMS measurements for complex 1 with PG were performed under the same conditions as for the respective experiments with gold, recording the mass traces for $\mathrm{O}_{2}$ and $\mathrm{CO}_{2}$ while cycling the potential between 1.3 and $2.0 \mathrm{~V}$ at 1 $\mathrm{mV} / \mathrm{s}$ with a starting potential of $1.3 \mathrm{~V}$. The recorded current (Figure 6, bottom) shows two oxidation events in the forward scan from around $1.6 \mathrm{~V}$ onward. The corresponding $\mathrm{O}_{2}$ trace (Figure 6, top) shows that oxygen evolution follows the recorded current profile, which suggests that both oxidation waves correspond to an oxygen evolution reaction. It appears that the formation of dioxygen is feasible for complex 1 in combination with a PG working electrode starting around 1.6 $\mathrm{V}$, whereas with a gold working electrode this is not the case until about 1.9 V. (compare Figure 6, top and bottom, with Figure 4, top and bottom).

Aside from oxygen evolution, significant amounts of $\mathrm{CO}_{2}$ are produced simultaneously at oxidative potentials when a PG working electrode is used (Figure 6, middle). While it is difficult to unambiguously assign either the complex or the electrode material as the source of the $\mathrm{CO}_{2}$, the results obtained when a gold working electrode is used suggest that most of the $\mathrm{CO}_{2}$ does indeed originate from the oxidation of pyrolytic graphite. This hypothesis is supported by the observation that, for a solution containing $\mathrm{Fe}(\mathrm{OTf})_{2}$ instead 

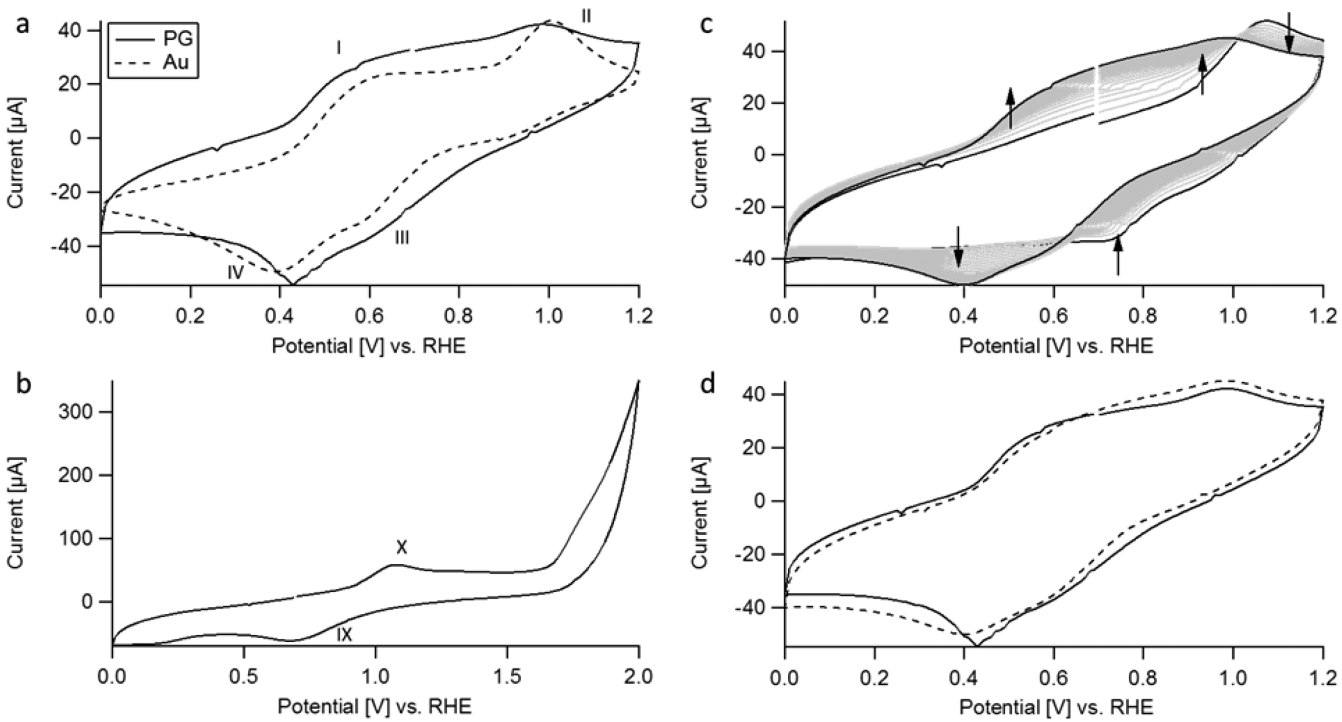

Figure 5. Shown are several voltammograms of $0.5 \mathrm{mM}$ complex 1 in a $0.1 \mathrm{M} \mathrm{Na}_{2} \mathrm{SO}_{4}$, recorded at $100 \mathrm{mV} / \mathrm{s}$, each with a starting potential of $0.7 \mathrm{~V}$ vs RHE. (a) Results of scanning between 0.0 and $1.2 \mathrm{~V}$ vs RHE on a PG working electrode and a gold working electrode. The current recorded for the gold working electrode was normalized by a factor of 3 for the sake of comparison. Shown is the second scan of each experiment. (b) Results of scanning between 0.0 and $2.0 \mathrm{~V}$ vs RHE on a PG working electrode. (c) 50 cycles between 0.0 and $1.2 \mathrm{~V}$ vs RHE, recorded on a PG working electrode immediately after scanning to $2.0 \mathrm{~V}$ vs RHE. The first and last scans are displayed in black, while the intermediate scans are displayed in gray. Arrows indicate the change in the current profile over time. (d) Comparison between the redox events recorded on a PG working electrode before scanning to $2.0 \mathrm{~V}$ vs RHE (solid line) and scan number 50 after scanning to $2.0 \mathrm{~V}$ vs RHE (dashed line).

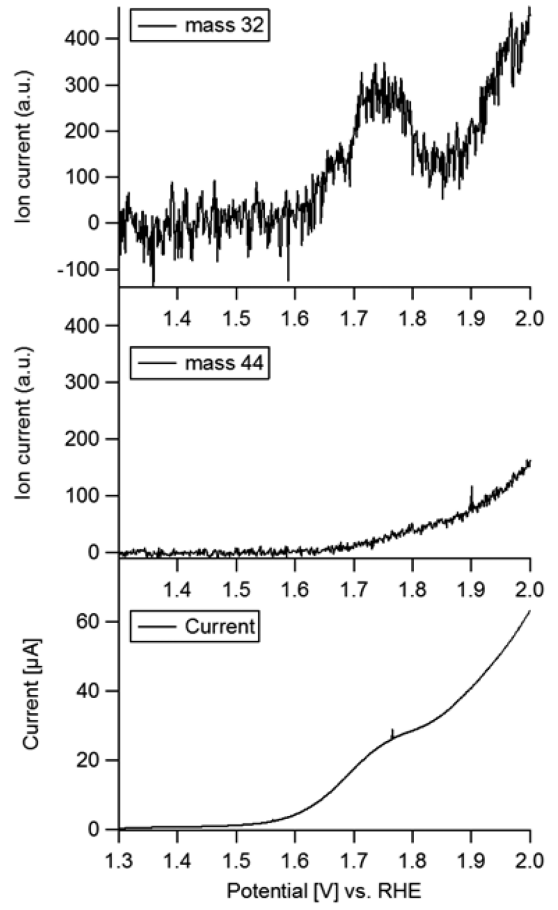

Figure 6. Results of an OLEMS measurement for $0.5 \mathrm{mM}$ complex 1 on a PG working electrode in a $0.1 \mathrm{M} \mathrm{Na}_{2} \mathrm{SO}_{4}$ solution (scan range $1.3-2.0 \mathrm{~V}$ vs RHE, scan rate $1 \mathrm{mV} / \mathrm{s}$, starting at $1.3 \mathrm{~V}$ vs RHE). Shown are the forward scan of a CV experiment with the $\mathrm{m} / z$ trace for $\mathrm{O}_{2}$ (top), the $m / z$ trace for $\mathrm{CO}_{2}$ (middle), and the corresponding current (bottom).

of complex $1, \mathrm{CO}_{2}$ formation of the same order of magnitude with roughly the same onset potential is observed (vide infra).

In contrast to gold, a PG working electrode does not produce any detectable amounts of oxygen in the absence of an additional catalyst even at potentials significantly greater than
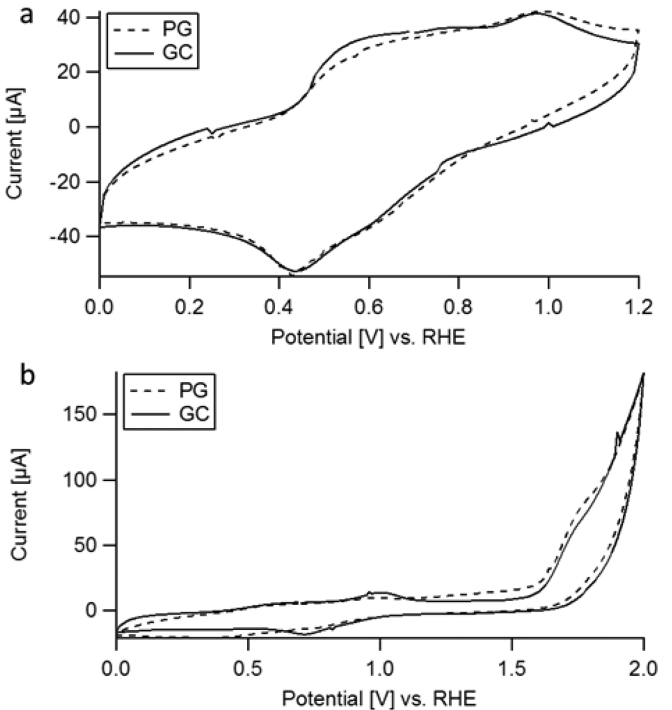

Figure 7. Voltammograms of $0.5 \mathrm{mM}$ complex 1 in a $0.1 \mathrm{M} \mathrm{Na}_{2} \mathrm{SO}_{4}$ solution recorded on different working electrodes. (a) Comparison of the results using PG and GC working electrodes. Shown is the respective second scan of each experiment, recorded between 0.0 and $1.2 \mathrm{~V}$ vs RHE at $100 \mathrm{mV} / \mathrm{s}$ with a starting potential of $0.7 \mathrm{~V}$ vs RHE. The current recorded on GC was normalized by a factor of 4.5 for the sake of comparison. (b) Comparison of the results using PG and GC working electrodes. Shown is the respective second scan of each experiment, recorded between 0.0 and $2.0 \mathrm{~V}$ vs RHE at $10 \mathrm{mV} / \mathrm{s}$ with a starting potential of $0.7 \mathrm{~V}$ vs RHE. The current recorded on GC was normalized by a factor of 4.5 for the sake of comparison.

2.0 V (Figure S7 in the Supporting Information). This shows clearly that the presence of complex $\mathbf{1}$ is crucial for the formation of dioxygen observed during the experiment.

The apparent difference in reactivity of complex 1 between experiments with a gold working electrode and a PG working electrode prompted us to look further into the correlation 

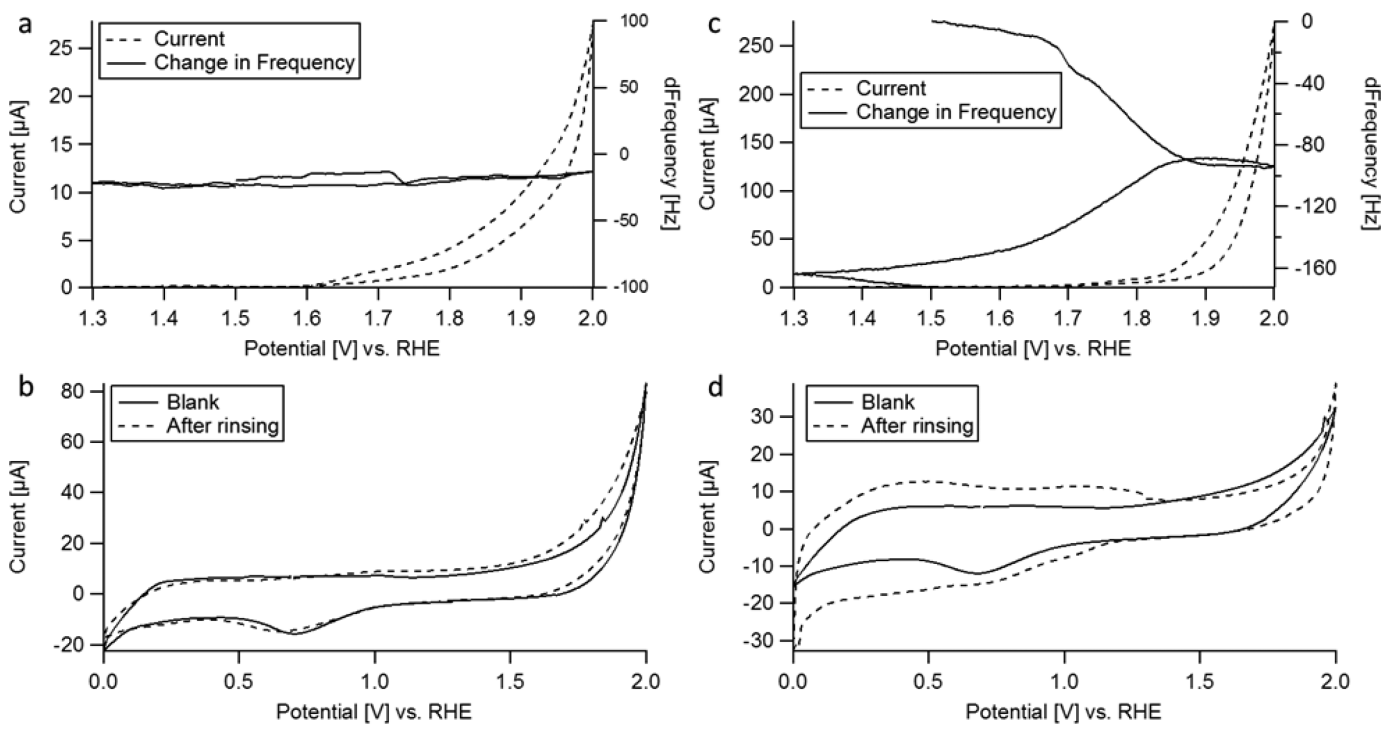

Figure 8. (a) Results of an EQCM experiment of $0.5 \mathrm{mM}$ complex 1 in a $0.1 \mathrm{M} \mathrm{Na}_{2} \mathrm{SO}_{4}$ solution, recorded between 1.3 and $2.0 \mathrm{~V}$ vs $\mathrm{RHE}$ with a gold working electrode at $1 \mathrm{mV} / \mathrm{s}$, starting at $1.5 \mathrm{~V}$ vs RHE. (b) Voltammograms of a freshly polished PG working electrode in a blank solution of $0.1 \mathrm{M} \mathrm{Na}_{2} \mathrm{SO}_{4}$ and the same PG working electrode in a blank $0.1 \mathrm{M} \mathrm{Na}_{2} \mathrm{SO}_{4}$ solution after cycling three times between 1.3 and $2.0 \mathrm{~V}$ vs $\mathrm{RHE}$ at 1 $\mathrm{mV} / \mathrm{s}$ in the presence of $0.5 \mathrm{mM}$ complex 1 in a $0.1 \mathrm{M} \mathrm{Na}_{2} \mathrm{SO}_{4}$ solution and subsequent rinsing in the electrode. Both voltammograms were recorded between 0.0 and $2.0 \mathrm{~V}$ vs RHE at $10 \mathrm{mV} / \mathrm{s}$, starting at $0.7 \mathrm{~V}$ vs RHE. (c) Result of an EQCM experiment of $1 \mathrm{mM} \mathrm{Fe}(\mathrm{OTf})_{2}$ in $0.1 \mathrm{M}$ $\mathrm{Na}_{2} \mathrm{SO}_{4}$, recorded between 1.3 and $2.0 \mathrm{~V}$ vs RHE with a gold working electrode at $1 \mathrm{mV} / \mathrm{s}$, starting at $1.5 \mathrm{~V}$ vs RHE. (d) Voltammograms of a freshly polished PG working electrode in a blank solution of $0.1 \mathrm{M} \mathrm{Na}_{2} \mathrm{SO}_{4}$ and the same PG working electrode in a blank $0.1 \mathrm{M} \mathrm{Na}_{2} \mathrm{SO}_{4}$ solution after cycling three times between 1.3 and $2.0 \mathrm{~V}$ vs RHE at $1 \mathrm{mV} / \mathrm{s}$ in the presence of $1 \mathrm{mM} \mathrm{Fe}(\mathrm{OTf})_{2}$ in a $0.1 \mathrm{M} \mathrm{Na}_{2} \mathrm{SO}_{4}$ solution and subsequent rinsing in the electrode. Both voltammograms were recorded between 0.0 and $2.0 \mathrm{~V}$ vs RHE at $10 \mathrm{mV} / \mathrm{s}$, starting at $0.7 \mathrm{~V}$ vs RHE.

between the properties of the electrode surface and the resulting electrochemistry. Using a glassy-carbon (GC) working electrode in combination with complex 1 yields results that are qualitatively identical with those obtained on PG, with respect to both the redox behavior (Figure $7 \mathrm{a}, \mathrm{b}$ ) and the two oxidation waves above $1.6 \mathrm{~V}$ (Figure $7 \mathrm{~b}$ ). Voltammograms recorded with a boron-doped-diamond (BDD) working electrode instead only show a single oxidation event above $1.6 \mathrm{~V}$ (Figure S8 in the Supporting Information), similar to the results for a gold working electrode, instead of the two distinct waves observed for graphitic electrode materials. A comparison among the results obtained for the four different electrode materials points to different modes of activity for complex 1 on graphitic working electrodes in comparison to nongraphitic working electrodes.

Homogeneous Catalyst vs Heterogeneous Surface Deposit. Since $\mathrm{Fe}_{2} \mathrm{O}_{3}$ is known to be a catalyst for water oxidation, ${ }^{51-54}$ it is important to establish that no such deposits are being formed on the working electrode, which then may be responsible for (part of) the observed reactivity. To rule out the formation of catalytically active surface deposits, electrochemical quartz crystal microbalance (EQCM) experiments were carried out with a gold working electrode. ${ }^{55,56}$ The results show no significant change in the mass of the electrode for the potential window between 1.3 and $2.0 \mathrm{~V}$ at $1 \mathrm{mV} / \mathrm{s}$ in the presence of complex 1 (Figure 8a).

The long-term stability of complex 1 was evaluated by means of EQCM in combination with chronoamperometry. At $1.9 \mathrm{~V}$ vs RHE no significant change in the mass of the electrode was observed over the course of $8 \mathrm{~h}$ (Figure S9 in the Supporting Information).

Since no graphitic EQCM electrodes were available, a PG working electrode was instead cycled three times between 1.3 and $2.0 \mathrm{~V}$ at a scan rate of $1 \mathrm{mV} / \mathrm{s}$ in the presence of complex 1 , taken out of the electrolyte solution, and rinsed. A subsequently recorded voltammogram measured in a $0.1 \mathrm{M} \mathrm{Na}_{2} \mathrm{SO}_{4}$ electrolyte solution in the absence of complex 1 showed no additional current above the background of a blank measurement (Figure $8 \mathrm{~b}$ ). These results show that, if any electrode deposition does occur during catalytic water oxidation mediated by complex 1, it must be a highly reversible process.

In contrast to the results obtained for complex 1, EQCM experiments in the presence of $1 \mathrm{mM} \mathrm{Fe}(\mathrm{OTf})_{2}$ show a clear change in the mass of the gold electrode under identical conditions, indicating the formation of a deposit on the electrode surface (Figure 8c). Similarly, cycling a PG working electrode three times between 1.3 and $2.0 \mathrm{~V}$ at $1 \mathrm{mV} / \mathrm{s}$ in the presence of $\mathrm{Fe}(\mathrm{OTf})_{2}$ with subsequent rinsing of the electrode and recording a $\mathrm{CV}$ measurement between 0.0 and $2.0 \mathrm{~V}$ in a $0.1 \mathrm{M} \mathrm{Na}_{2} \mathrm{SO}_{4}$ electrolyte solution without $\mathrm{Fe}(\mathrm{OTf})_{2}$ present yield a voltammogram which is different from that of a blank measurement (Figure 8d). OLEMS measurements of Fe(OTf $)_{2}$ on a PG working electrode reveal water oxidation activity, albeit with a different current profile and higher onset potential for the oxygen evolution reaction in comparison to complex 1 (Figure S10 in the Supporting Information).

The ion current for $\mathrm{CO}_{2}$ measured with a PG working electrode in the presence of complex 1 and $\mathrm{Fe}(\mathrm{OTf})_{2}$, respectively, is of the same order of magnitude (compare Figure 6, middle, with Figure S10 in the Supporting Information, middle), despite $\mathrm{Fe}(\mathrm{OTf})_{2}$ lacking any ligand that could conceivably be oxidized to $\mathrm{CO}_{2}$ under these conditions, providing further evidence for the assumption that the $\mathrm{CO}_{2}$ formation observed in OLEMS experiments with complex 1 on a PG working electrode originates predominantly from the oxidation of the electrode material rather than oxidation of the ligand. 
Mechanistic Considerations. For PG, GC, and $\mathrm{Au}$ working electrodes, we found that the redox behavior of complex $\mathbf{1}$ in solution changes upon exposure to high potentials. When the complex is kept at lower potentials afterward, it slowly reverts to the original behavior (Figures 3 and $5 \mathrm{c}, \mathrm{d})$. Since mass spectrometry and UV-vis spectroscopy show that complex 1 exists exclusively as a dimer at the start of the experiment, this reversibility means that the dimeric structure is regenerated at lower potentials. A possible explanation could be that the complex falls apart into two $\mathrm{Fe}$ (Hbbpya) monomers upon oxidation to the $\mathrm{Fe}^{\mathrm{IV}}$ or $\mathrm{Fe}^{\mathrm{V}}$ state which reassociate to form complex 1 in the $\mathrm{Fe}^{\mathrm{III}}$ state.

Evidence for the molecular nature of the catalytically active species was obtained from EQCM experiments on gold, in which no mass changes of the electrode were observed in the presence of complex 1 under catalytic conditions. From control experiments with $\mathrm{Fe}(\mathrm{OTf})_{2}$ instead of complex 1 we can rule out any potential pathways involving decoordination of the Hbbpya ligand leading to the subsequent formation of the active catalyst in the form of solid deposits on the electrode surface.

For the combination of complex 1 with graphitic working electrodes, oxygen evolution was observed already at significantly lower potentials in comparison to complex 1 in combination with other electrode materials. This suggests that the first oxidation wave above $1.6 \mathrm{~V}$ seen on both PG and GC (Figure $7 \mathrm{~b}$ ) might be related to specific interactions between the catalyst and a graphitic electrode surface. The difference in oxygen evolution activity of complex 1 on a graphitic working electrode in comparison to a gold working electrode strongly suggests a mechanism other than the involvement of surface oxides which has previously been suggested for a flavin-based water oxidation catalyst. ${ }^{41}$ Instead, hydrophobic interactions, for example, in the form of $\pi-\pi$ stacking between the aromatic Hbbpya ligand and an $\mathrm{sp}^{2}$ carbon surface might take place. ${ }^{57-62}$ The substrate influence of graphitic electrodes has an apparent beneficial influence on the water oxidation capabilities of complex 1, leading to a significantly earlier onset of oxygen evolution on PG and GC working electrodes in comparison to BDD and gold working electrodes.

When comparing the voltammograms recorded for a PG working electrode in a blank $0.1 \mathrm{M} \mathrm{Na}_{2} \mathrm{SO}_{4}$ solution before and after being cycled three times between 1.3 and $2.0 \mathrm{~V}$ at $1 \mathrm{mV} / \mathrm{s}$ in the presence of complex 1, we found no difference in the recorded current. This means that the interaction between complex $\mathbf{1}$ and the surface of a graphitic electrode must be highly reversible in nature and does not lead to the formation of a lasting adsorbed state.

Kinetic Considerations. At the relatively low currents that we record, the most reliable technique to determine the Faradaic efficiency is the use of a rotating ring disk electrode (RRDE) setup. Due to rotation of the electrode, the electrolyte flows from the disk, where water oxidation occurs, to the ring, where dioxygen is reduced and can be quantified. This experiment is not straightforward in the case of a homogeneous catalyst, since both the catalyst and dioxygen are diffusive species. This means that partially oxidized catalytic species and dioxygen can both be reduced on the ring. As a result, the current at the disk electrode is made up of three parts: current caused by catalytic water oxidation, reversible oxidation of the catalyst, and losses from irreversible side reactions such as $\mathrm{CO}_{2}$ formation.
The contributions from reversible oxidation of dissolved complex in solution and formation of dioxygen were disentangled by two separate RRDE experiments. Using a Pt ring electrode set to $0.5 \mathrm{~V}$ vs RHE in combination with a PG disk electrode allows us to determine the sum of the current caused by oxidation of complex and dioxygen formation (Figure S13 in the Supporting Information). The amount of current caused only by reversible oxidation of the complex was then quantified separately in a second experiment using a ring electrode made from GC instead of $\mathrm{Pt}$, as the GC ring electrode does not reduce dioxygen at a potential of $0.5 \mathrm{~V}$ vs $\mathrm{RHE}$ (Figure S14 in the Supporting Information). The maximum overall collection efficiency for the setup was then determined with $\mathrm{K}_{3}\left[\mathrm{Fe}(\mathrm{CN})_{6}\right]$ using a PG disk electrode and Pt ring electrode (Figure S15 in the Supporting Information).

For complex 1 we find the following contributions to the current. At $1.75 \mathrm{~V} 26 \%$ of the current is due to dioxygen formation and $23 \%$ is due to reversible losses. The remaining $51 \%$ is then attributed to irreversible losses. At $2.0 \mathrm{~V}$ we found $32 \%$ of current due to dioxygen formation, $33 \%$ due to reversible losses, and 35\% due to irreversible losses.

The Faradaic efficiencies of dioxygen formation that we found are largely underestimated for two reasons. First, due to rotation, the transient time of catalytic species over the disk is limited and may be too short to complete a catalytic cycle. This results in a considerable amount of partially oxidized species that are reduced back at the ring. At a stationary electrode such species may complete the catalytic cycle to produce dioxygen. Attempts to further reduce the rotation speed and thereby increase the transient time of catalytic species over the disk resulted in a delayed response on the ring and were abandoned. Second, due to the low solubility of $\mathrm{O}_{2}$ in water, the collection efficiency of dioxygen on the ring can be significantly lower than that of other species, such as ferricyanide, which was used to determine the collection efficiency of the setup. In a separate RRDE experiment using a Pt disk electrode and a Pt ring electrode, we found a Faradaic efficiency for oxygen evolution of only $68 \%$ at $1.7 \mathrm{~V}$. As a result, the turnover frequencies mentioned below for water oxidation catalyzed by complex 1 should be considered as conservative estimates.

We used eq 1 in combination with the Faradaic efficiency obtained from RRDE experiments to determine the TOF of complex 1 at different overpotentials. In this equation, $\nu$ is the scan rate of the experiment, $i_{\mathrm{p}}$ is the current of oxidation wave $\mathrm{X}$ (cf. Figures 2 and 5), and $i_{\text {cat }}$ is the catalytic current at the potential for which the TOF is to be determined. Additional details about the calculations and $\mathrm{RRDE}$ experiments are available in the Supporting Information.

$$
\mathrm{TOF}=0.4848 \nu\left(\frac{i_{\mathrm{cat}}}{i_{\mathrm{p}}}\right)^{2}
$$

The results show that the TOF increases as the applied potential increases. At $1.75 \mathrm{~V}$ we found a TOF of $0.12 \mathrm{~s}^{-1}$ for complex 1, which increases to $1.2 \mathrm{~s}^{-1}$ at $2.0 \mathrm{~V}$. This demonstrates that electron-transfer kinetics remain rate limiting until at least $2.0 \mathrm{~V}$ vs RHE.

A comparison of the catalytic performance with data from the literature is complicated by the fact that the majority of kinetic studies have been carried out in the presence of chemical oxidants rather than by electrochemical means, which leads to a poorly defined overpotential for those cases. However, the rates determined for complex 1 with graphitic 
working electrodes compare favorably to values reported in the literature, as most iron-based catalysts have been reported to exhibit TOFs on the order of $0.1 \mathrm{~s}^{-1}$ or lower in water. Typical examples range from $0.012 \mathrm{~s}^{-1}$ reported by Akermark et al. to $0.23 \mathrm{~s}^{-1}$ for the $\mathrm{Fe}(\mathrm{mcp})$ system reported by Costas et al. ${ }^{26,27}$ Some notable exceptions are the Fe(TAML) system by Collins et al. and the $\mathrm{Fe}$ (ppq) system by Thummel et al., for which initial rates of 1.3 and $2.2 \mathrm{~s}^{-1}$, respectively, were found in the presence of excess CAN. ${ }^{15,22}$ In addition, it is also important to note that 1 shows a significantly earlier onset for the OER by approximately $0.2 \mathrm{~V}$ in comparison to a series of $\mathrm{Fe}$ (cyclam) complexes that were reported earlier under identical reaction conditions, also using PG working electrodes. ${ }^{18}$

\section{CONCLUSIONS}

Complex 1 was found to be active as an electrocatalyst for the water oxidation reaction. Results obtained from EQCM experiments rule out the possibility of the formation of a solid deposit on the electrode surface as the true catalytic species, highlighting the stability of complex 1 under catalytic conditions and providing evidence for the molecular nature of the catalytically active species.

The results of CV experiments show a clear shift in the observed $\mathrm{Fe}^{\mathrm{II}} / \mathrm{Fe}^{\mathrm{III}}$ redox behavior after exposure of complex 1 to high potentials $(2.0 \mathrm{~V}$ vs RHE), which suggests that complex $\mathbf{1}$ is merely the precatalyst and not the true active species. However, in a subsequent $\mathrm{CV}$ experiment the original redox behavior of complex 1 was recovered over time, showing that the change in redox behavior is reversible and that the dimeric structure of complex $\mathbf{1}$ is regenerated.

In comparison to other iron-based water oxidation electrocatalysts, complex 1 exhibits a remarkably low onset potential of oxygen evolution in combination with a PG working electrode, with a recorded overpotential on the scale of only $300-400 \mathrm{mV}$ with respect to the thermodynamic potential of the water oxidation reaction of $1.23 \mathrm{~V}$. On the basis of a comparison of the catalytic behavior of complex 1 with working electrodes made up of different materials, the onset potential of oxygen evolution observed in the case of graphitic working electrodes is significantly lower in comparison to experiments with a gold working electrode, demonstrating a strong substrate influence of the electrode material on the catalytic performance. This means that for any attempts to benchmark water oxidation catalysts electrochemically a possible influence of the electrode material must be considered.

While our results show that using graphitic working electrodes in combination with complex 1 has clear advantages over using gold working electrodes in terms of catalyst performance, $\mathrm{CO}_{2}$ formation from graphite electrodes represents a potential drawback that one would have to consider for sustainable fuel production applications. To the best of our knowledge, our findings represent the first evidence that substrate effects of the electrode material can lead to a significant reduction of the overpotential of a homogeneous electrocatalyst for the water oxidation reaction, emphasizing the importance of the electrode material in electrocatalytic applications.

\section{EXPERIMENTAL SECTION}

Materials and Instrumentation. tert-Butylamine was purchased from Acros Organics. 2,2'-Bipyridine, $m \mathrm{CPBA}$, 6bromo-2,2'-bipyridine, $(S)$-BINAP, iron powder, $\mathrm{PhCF}_{3}$, and
KOtBu were purchased from Sigma-Aldrich. $p$-Toluenesulfonic acid anhydride was purchased from VWR. Pd $(\mathrm{dba})_{2}$, TFA, and MTBE were purchased from Fisher Scientific. All chemicals were used as received without further purification. The concentration of mCPBA was determined via titration with sodium thiosulfate before use. ( $S$ )-BINAP, iron powder, $\mathrm{PhCF}_{3}$, and $\mathrm{KO} t \mathrm{Bu}$ were stored under argon.

2,2'-Bipyridine mono- $N$-oxide, 6-amino-2,2' -bipyridine, and $N, N$-bis $\left(2,2^{\prime}\right.$-bipyrid-6-yl)amine were synthesized according to literature procedures. ${ }^{63-65}$ Solvents were degassed according to standard freeze-pump-thaw protocols.

UV-vis spectra were recorded on a Varian Cary 50 Scan spectrophotometer. Mass spectra were measured on a Thermo Scientific MSQPlus ESI spectrometer. Elemental analyses were performed by Mikroanalytisches Laboratorium Kolbe in Germany.

Electrochemical Experiments. All electrochemical measurements with the exception of the EQCM and RRDE experiments (details below) were performed in custom-made single-compartment glass cells, recorded on Ivium potentiostats, and operated by IviumSoft software, using a threeelectrode setup with the working electrode in hanging meniscus configuration. The working electrodes used in the experiments were a pyrolytic graphite (PG) disk, two gold disk electrodes of different sizes, a glassy-carbon (GC) rod, and a boron-dopeddiamond (BDD) disk. The respective (geometric) surface areas are $0.2 \mathrm{~cm}^{2}$ (PG), 0.13 and $0.5 \mathrm{~cm}^{2}$ (gold), and $0.07 \mathrm{~cm}^{2}$ (GC and $\mathrm{BDD})$. A large surface area gold plate was used as a counter electrode in all experiments. The reference electrode was a reversible hydrogen electrode (RHE) made up of a platinum mesh in $\mathrm{H}_{2}$-saturated electrolyte at the same $\mathrm{pH}$ as the electrolyte solution inside the cell. The cell and the reference electrode were connected via a Luggin capillary.

The PG electrode was prepared before each experiment by polishing the electrode surface with sandpaper. The GC electrode was prepared by polishing the electrode surface with sandpaper first and subsequently with alumina suspensions $(1.0 \mu \mathrm{m}$ followed by $0.3 \mu \mathrm{m})$. For both the PG and the GC electrodes, the polishing was followed by removal of excess debris by sonicating the electrode in Milli-Q water for at least 5 min.

The gold electrodes were prepared before each experiment by oxidizing the surface at $10 \mathrm{~V}$ for $30 \mathrm{~s}$ in a $10 \% \mathrm{H}_{2} \mathrm{SO}_{4}$ solution, followed by stripping of the gold oxide layer in a $6 \mathrm{M}$ $\mathrm{HCl}$ solution and subsequent electropolishing of the electrode by scanning for 200 cycles between 0.0 and $1.75 \mathrm{~V}$ vs RHE at $1000 \mathrm{mV} / \mathrm{s}$ in a $0.1 \mathrm{M} \mathrm{HClO}_{4}$ electrolyte solution.

The BDD electrode was prepared before each experiment by sonication for $5 \mathrm{~min}$ in concentrated $\mathrm{HNO}_{3}$ followed by sonication for $5 \mathrm{~min}$ in Milli-Q water.

All glassware used in electrochemical measurements was routinely cleaned of any organic contamination by boiling in a $3 / 1$ mixture of concentrated sulfuric and nitric acid. Prior to each experiment, the glassware was cleaned by 3-fold rinsing and boiling in Milli- $\mathrm{Q}$ water. All electrolyte solutions were prepared from p.a. grade chemicals (Merck Suprapur) and Milli-Q water (resistivity $>18.2 \mathrm{M} \Omega$ ). Prior to measurements, the electrolyte solution was purged of air by bubbling with argon (Linde, Ar 6.0) for at least $20 \mathrm{~min}$. During the measurements, the cell was constantly kept under argon flow to prevent air from entering.

Due to slow dissolution of complex 1 in $0.1 \mathrm{M} \mathrm{Na}_{2} \mathrm{SO}_{4}$ electrolyte solution, the complex was initially dissolved in a 
small amount of Milli-Q water (typically $1-2 \mathrm{~mL}$ ) and subsequently added to the electrochemical cell containing the electrolyte solution. The concentration of electrolyte in the cell was adjusted to account for the resulting dilution. All experiments in this report were performed at a catalyst concentration of $0.5 \mathrm{mM}$.

For the OLEMS measurements, the gases formed at the working electrode were collected via a hydrophobic tip (KEL-F with a porous Teflon plug) in close proximity to the surface of the working electrode and analyzed in a QMS 200 mass spectrometer. A detailed description of the OLEMS setup is available elsewhere. ${ }^{45}$ For the mass spectrometry data recorded during cyclic voltammetry, background correction was done by assuming an exponential decay fit (see Figures 4 and 6 and Figures S6 and S10 in the Supporting Information).

EQCM experiments were performed in a $3 \mathrm{~mL}$ Teflon cell purchased from Autolab. The top part of the cell was modified to allow for electrochemical measurements under an inert atmosphere. For further details, see Figure S11 in the Supporting Information. The EQCM was controlled by an Autolab potentiostat operated by NOVA 2.0 software. Autolab EQCM electrodes with a surface area of $1.5 \mathrm{~cm}^{2}$ consisting of a $200 \mathrm{~nm}$ gold layer deposited on a quartz crystal were used as working electrodes. A custom-made RHE reference electrode was used which is described elsewhere. ${ }^{46}$

RRDE experiments were performed in a large singlecompartment glass cell with a Pine rotator, using Pt and GC ring electrodes and a PG disk electrode purchased from Pine. All ring and disk electrodes were polished with alumina suspensions (1.0, 0.3, and $0.05 \mu \mathrm{m})$ before use. The Pt electrodes were subsequently treated with electropolishing by cycling the potential between -0.5 and $2.0 \mathrm{~V}$ vs RHE for 100 cycles at a scan rate of $500 \mathrm{mV} / \mathrm{s}$ before the experiment. The maximum collection efficiency was determined in a separate experiment using the ferrocyanide/ferricyanide redox couple $\left(0.5 \mathrm{mM} \mathrm{K} \mathrm{K}_{3}\left[\mathrm{Fe}(\mathrm{CN})_{6}\right]\right.$ in a $0.1 \mathrm{M} \mathrm{Na}_{2} \mathrm{SO}_{4}$ electrolyte solution). The RRDE was controlled by an Autolab potentiostat operated by NOVA 2.0 software.

Synthesis of $\mathrm{Fe}(\mathrm{OTf})_{2} \cdot \mathbf{5 . 5} \mathrm{H}_{2} \mathrm{O}$. Iron powder $(1.44 \mathrm{~g}, 25.8$ $\mathrm{mmol}$ ) was carefully added in portions to $4.5 \mathrm{~mL}$ of $98 \%$ triflic acid $(50.0 \mathrm{mmol})$ in $30 \mathrm{~mL}$ of water at room temperature with stirring. After all gas evolution ceased, the mixture was heated to $60{ }^{\circ} \mathrm{C}$ for $1 \mathrm{~h}$ while stirring was maintained. The remaining solids were removed by filtration, and the water was evaporated under vacuum, yielding a white powder with a slight blue-green hue which was dried under vacuum. Yield: $8.6 \mathrm{~g}$ (19.0 mmol, $76 \%)$. The compound was stored under argon to prevent subsequent changes in the hydration state over time. Anal. Calcd for $\mathrm{C}_{2} \mathrm{~F}_{6} \mathrm{Fe}_{2} \mathrm{O}_{6} \mathrm{~S}_{2} \cdot 5.5 \mathrm{H}_{2} \mathrm{O}(453.0 \mathrm{~g} / \mathrm{mol})$ : C, 5.30; $\mathrm{H}$, 2.45; N, 0.00. Found: C, 5.28; H ,2.46; N, 0.00 .

Synthesis of [(MeOH)Fe(Hbbpya)- $\mu$-O-(Hbbpya)Fe$(\mathrm{MeOH})](\mathrm{OTf})_{4}$ (1). N,N-Bis(2,2'-bipyrid-6-yl)amine $(24 \mathrm{mg}$, $0.07 \mathrm{mmol}$ ) was dissolved in $2 \mathrm{~mL}$ of degassed methanol. Subsequently $\mathrm{Fe}(\mathrm{OTf})_{2} \cdot 5.5 \mathrm{H}_{2} \mathrm{O}(34 \mathrm{mg}, 0.07 \mathrm{mmol})$ dissolved in $2 \mathrm{~mL}$ of degassed methanol was added, resulting in a deep red solution. The mixture was stirred overnight under a $\mathrm{N}_{2}$ atmosphere at room temperature. After removal of the solvent under vacuum, the obtained crude product was dissolved in a small amount of methanol $(\sim 1 \mathrm{~mL})$. Complex 1 was obtained as dark brown crystals through slow vapor diffusion of diethyl ether into a methanolic solution of the crude product in air. The crystals were collected by filtration, washed with diethyl ether followed by washing with a small amount of cold methanol, and subsequently dried in air. Yield: $39 \mathrm{mg}(0.03$ mmol, 73\%). ESI-MS $\left(\mathrm{H}_{2} \mathrm{O}\right)$ : found [ $\left[\mathrm{Fe}^{\mathrm{III}}(\right.$ bbpya $)-\mu-\mathrm{O}-$ (bbpya)Fe $\left.{ }^{\mathrm{III}}\right]^{2+} m / z$ 388.6, calcd $m / z$ 388.1. Anal. Calcd for $\mathrm{C}_{46} \mathrm{H}_{38} \mathrm{~F}_{12} \mathrm{Fe}_{2} \mathrm{~N}_{10} \mathrm{O}_{15} \mathrm{~S}_{4} \cdot 2 \mathrm{H}_{2} \mathrm{O}$ (1474.0 g/mol): C, 37.46; $\mathrm{H}$, 2.87; N, 9.50. Found: C, 37.61; H, 2.91; N, 9.63.

\section{ASSOCIATED CONTENT}

\section{Supporting Information}

The Supporting Information is available free of charge on the ACS Publications website at DOI: 10.1021/acscatal.7b03284.

Additional figures as described in the text and crystallographic data for complex $\mathbf{1}$ (PDF)

Crystallographic data for complex 1 (CIF)

\section{AUTHOR INFORMATION}

\section{Corresponding Author}

*E-mail for D.G.H.H.: d.g.h.hetterscheid@chem.leidenuniv.nl. ORCID

Dennis G. H. Hetterscheid: 0000-0001-5640-4416

Notes

The authors declare no competing financial interest.

\section{ACKNOWLEDGMENTS}

We thank Prof. E. Bouwman and Prof. M. T. M. Koper for helpful discussions. The Netherlands Organization for Scientific Research (NWO) is acknowledged for financial support (Echo grant 717.014.008).

\section{REFERENCES}

(1) Lewis, N. S.; Nocera, D. G. Proc. Natl. Acad. Sci. U. S. A. 2006, 103, 15729-15735.

(2) Lewis, N. S. Science 2007, 315, 798-801.

(3) Concepcion, J. J.; Jurss, J. W.; Hoertz, P. G.; Meyer, T. J. Angew. Chem., Int. Ed. 2009, 48, 9473-9476.

(4) Duan, L.; Bozoglian, F.; Mandal, S.; Stewart, B.; Privalov, T.; Llobet, A.; Sun, L. Nat. Chem. 2012, 4, 418-423.

(5) Lalrempuia, R.; McDaniel, N. D.; Muller-Bunz, H.; Bernhard, S.; Albrecht, M. Angew. Chem., Int. Ed. 2010, 49, 9765-9768.

(6) Wasylenko, D. J.; Palmer, R. D.; Berlinguette, C. P. Chem. Commun. 2013, 49, 218-227.

(7) Blakemore, J. D.; Crabtree, R. H.; Brudvig, G. W. Chem. Rev. 2015, 115, 12974-13005.

(8) Sala, X.; Romero, I.; Rodriguez, M.; Escriche, L.; Llobet, A. Angew. Chem., Int. Ed. 2009, 48, 2842-2852.

(9) Hetterscheid, D. G.; Reek, J. N. Angew. Chem., Int. Ed. 2012, 51, 9740-9747.

(10) Diaz-Morales, O.; Hersbach, T. J.; Hetterscheid, D. G.; Reek, J. N.; Koper, M. T. J. Am. Chem. Soc. 2014, 136, 10432-10439.

(11) Bucci, A.; Savini, A.; Rocchigiani, L.; Zuccaccia, C.; Rizzato, S.; Albinati, A.; Llobet, A.; Macchioni, A. Organometallics 2012, 31, 80718074.

(12) Menendez Rodriguez, G.; Bucci, A.; Hutchinson, R.; Bellachioma, G.; Zuccaccia, C.; Giovagnoli, S.; Idriss, H.; Macchioni, A. ACS Energy Letters 2017, 2, 105-110.

(13) Karkas, M. D.; Akermark, B. Dalton Trans. 2016, 45, 1442114461 .

(14) Najafpour, M. M.; Moghaddam, A. N.; Sedigh, D. J.; Hołyńska, M. Catal. Sci. Technol. 2014, 4, 30-33.

(15) Wickramasinghe, L. D.; Zhou, R.; Zong, R.; Vo, P.; Gagnon, K. J.; Thummel, R. P. J. Am. Chem. Soc. 2015, 137, 13260-13263.

(16) Wang, D.; Que, L., Jr. Chem. Commun. 2013, 49, 10682-10684.

(17) Okamura, M.; Kondo, M.; Kuga, R.; Kurashige, Y.; Yanai, T.; Hayami, S.; Praneeth, V. K.; Yoshida, M.; Yoneda, K.; Kawata, S.; Masaoka, S. Nature 2016, 530, 465-468. 
(18) Kottrup, K. G.; Hetterscheid, D. G. Chem. Commun. 2016, 52, 2643-2646.

(19) Demeter, E. L.; Hilburg, S. L.; Washburn, N. R.; Collins, T. J.; Kitchin, J. R. J. Am. Chem. Soc. 2014, 136, 5603-5606.

(20) Coggins, M. K.; Zhang, M. T.; Vannucci, A. K.; Dares, C. J.; Meyer, T. J. J. Am. Chem. Soc. 2014, 136, 5531-5534.

(21) Tan, P.; Kwong, H. K.; Lau, T. C. Chem. Commun. 2015, 51, 12189-12192.

(22) Ellis, W. C.; McDaniel, N. D.; Bernhard, S.; Collins, T. J. J. Am. Chem. Soc. 2010, 132, 10990-10991.

(23) Zhang, B.; Li, F.; Yu, F.; Cui, H.; Zhou, X.; Li, H.; Wang, Y.; Sun, L. Chem. - Asian J. 2014, 9, 1515-1518.

(24) Parent, A. R.; Nakazono, T.; Lin, S.; Utsunomiya, S.; Sakai, K. Dalton Trans. 2014, 43, 12501-12513.

(25) Hoffert, W. A.; Mock, M. T.; Appel, A. M.; Yang, J. Y. Eur. J. Inorg. Chem. 2013, 2013, 3846-3857.

(26) Fillol, J. L.; Codola, Z.; Garcia-Bosch, I.; Gomez, L.; Pla, J. J.; Costas, M. Nat. Chem. 2011, 3, 807-813.

(27) Das, B.; Lee, B. L.; Karlsson, E. A.; Akermark, T.; Shatskiy, A.; Demeshko, S.; Liao, R. Z.; Laine, T. M.; Haukka, M.; Zeglio, E.; AbdelMagied, A. F.; Siegbahn, P. E.; Meyer, F.; Karkas, M. D.; Johnston, E. V.; Nordlander, E.; Akermark, B. Dalton Trans. 2016, 45, 1328913293.

(28) Panchbhai, G.; Singh, W. M.; Das, B.; Jane, R. T.; Thapper, A. Eur. J. Inorg. Chem. 2016, 2016, 3262-3268.

(29) Wang, L.; Duan, L.; Wang, Y.; Ahlquist, M. S.; Sun, L. Chem. Commun. 2014, 50, 12947-12950.

(30) Matheu, R.; Ertem, M. Z.; Benet-Buchholz, J.; Coronado, E.; Batista, V. S.; Sala, X.; Llobet, A. J. Am. Chem. Soc. 2015, 137, 1078610795.

(31) Tamaki, Y.; Vannucci, A. K.; Dares, C. J.; Binstead, R. A.; Meyer, T. J. J. Am. Chem. Soc. 2014, 136, 6854-6857.

(32) Dogutan, D. K.; McGuire, R., Jr.; Nocera, D. G. J. Am. Chem. Soc. 2011, 133, 9178-9180.

(33) Codola, Z.; Gomez, L.; Kleespies, S. T.; Que, L., Jr.; Costas, M.; Lloret-Fillol, J. Nat. Commun. 2015, 6, 5865.

(34) Demars, T. J.; Bera, M. K.; Seifert, S.; Antonio, M. R.; Ellis, R. J. Angew. Chem., Int. Ed. 2015, 54, 7534-7538.

(35) Hetterscheid, D. G. H.; Reek, J. N. H. Eur. J. Inorg. Chem. 2014, 2014, 742-749.

(36) Parent, A. R.; Crabtree, R. H.; Brudvig, G. W. Chem. Soc. Rev. 2013, 42, 2247-2252.

(37) Wasylenko, D. J.; Ganesamoorthy, C.; Henderson, M. A.; Berlinguette, C. P. Inorg. Chem. 2011, 50, 3662-3672.

(38) Yoshida, M.; Masaoka, S.; Abe, J.; Sakai, K. Chem. - Asian J. 2010, 5, 2369-2378.

(39) Pecht, I.; Luz, Z. J. Am. Chem. Soc. 1965, 87, 4068-4072.

(40) Bard, A. J.; Faulkner, L. R. In Electrochemical methods: fundamentals and applications, 2nd ed.; Wiley: Hoboken, NJ, 2001; pp 115-117.

(41) Mirzakulova, E.; Khatmullin, R.; Walpita, J.; Corrigan, T.; Vargas-Barbosa, N. M.; Vyas, S.; Oottikkal, S.; Manzer, S. F.; Hadad, C. M.; Glusac, K. D. Nat. Chem. 2012, 4, 794-801.

(42) Sheehan, S. W.; Thomsen, J. M.; Hintermair, U.; Crabtree, R. H.; Brudvig, G. W.; Schmuttenmaer, C. A. Nat. Commun. 2015, 6, 6469.

(43) Calderazzo, F.; Labella, L.; Marchetti, F. J. Chem. Soc., Dalton Trans. 1998, 1485-1490.

(44) Martinez, C. R; Iverson, B. L. Chem. Sci. 2012, 3, 2191-2201.

(45) Wonders, A. H.; Housmans, T. H. M.; Rosca, V.; Koper, M. T.

M. J. Appl. Electrochem. 2006, 36, 1215-1221.

(46) Abril, P.; del Río, M. P.; Tejel, C.; Verhoeven, T. W. G. M.; Niemantsverdriet, J. W. H.; van der Ham, C. J. M.; Kottrup, K. G.; Hetterscheid, D. G. H. ACS Catal. 2016, 6, 7872-7875.

(47) Hintermair, U.; Sheehan, S. W.; Parent, A. R.; Ess, D. H.; Richens, D. T.; Vaccaro, P. H.; Brudvig, G. W.; Crabtree, R. H. J. Am. Chem. Soc. 2013, 135, 10837-10851.

(48) Limburg, B.; Bouwman, E.; Bonnet, S. Coord. Chem. Rev. 2012, $256,1451-1467$.
(49) Fukuzumi, S.; Hong, D. Eur. J. Inorg. Chem. 2014, 2014, 645659.

(50) Diaz-Morales, O.; Calle-Vallejo, F.; de Munck, C.; Koper, M. T. M. Chem. Sci. 2013, 4, 2334-2343.

(51) Chen, G.; Chen, L.; Ng, S. M.; Man, W. L.; Lau, T. C. Angew. Chem., Int. Ed. 2013, 52, 1789-1791.

(52) Lin, Y.; Zhou, S.; Sheehan, S. W.; Wang, D. J. Am. Chem. Soc. 2011, 133, 2398-2401.

(53) Mayer, M. T.; Du, C.; Wang, D. J. Am. Chem. Soc. 2012, 134, 12406-12409.

(54) Young, K. M. H.; Klahr, B. M.; Zandi, O.; Hamann, T. W. Catal. Sci. Technol. 2013, 3, 1660-1671.

(55) Schley, N. D.; Blakemore, J. D.; Subbaiyan, N. K.; Incarvito, C. D.; D'Souza, F.; Crabtree, R. H.; Brudvig, G. W. J. Am. Chem. Soc. 2011, 133, 10473-10481.

(56) van der Ham, C. J. M.; Iş1k, F.; Verhoeven, T. W. G. M.; Niemantsverdriet, J. W.; Hetterscheid, D. G. H. Catal. Today 2017, 290, 33-38.

(57) Björk, J.; Hanke, F.; Palma, C.-A.; Samori, P.; Cecchini, M.; Persson, M. J. Phys. Chem. Lett. 2010, 1, 3407-3412.

(58) Rochefort, A.; Wuest, J. D. Langmuir 2009, 25, 210-215.

(59) Chakarova-Kack, S. D.; Schroder, E.; Lundqvist, B. I.; Langreth, D. C. Phys. Rev. Lett. 2006, 96, 146107.

(60) Morales Vásquez, M. A.; Hamer, M.; Neuman, N. I.; Tesio, A. Y.; Hunt, A.; Bogo, H.; Calvo, E. J.; Doctorovich, F. ChemCatChem 2017, 9, 3259.

(61) Rajesh, C.; Majumder, C.; Mizuseki, H.; Kawazoe, Y. J. Chem. Phys. 2009, 130, 124911.

(62) Wang, Z.; Lei, H.; Cao, R.; Zhang, M. Electrochim. Acta 2015, 171, 81-88.

(63) Norrby, T.; Börje, A.; Zhang, L.; Åkermark, B.; Wagenknecht, J. H.; Francis, G. W.; Szúnyog, J.; Långström, B. Acta Chem. Scand. 1998, $52,77-85$.

(64) Yin, J.; Xiang, B.; Huffman, M. A.; Raab, C. E.; Davies, I. W. J. Org. Chem. 2007, 72, 4554-4557.

(65) Zheng, S.; Reintjens, N. R.; Siegler, M. A.; Roubeau, O.; Bouwman, E.; Rudavskyi, A.; Havenith, R. W.; Bonnet, S. Chem. - Eur. J. 2016, 22, 331-339. 